\title{
Quantitative determination of low molecular weight antioxidants and their effects on different antioxidants in chicken blood plasma
}

\author{
Petra Jazbec Krizman ${ }^{1}$, Andrej Smidovnik ${ }^{1}$, Alenka Golc Wondra ${ }^{1}$, Katarina Cernelic ${ }^{1}$, Darja Kotnik ${ }^{1}$, \\ Mitja Krizman ${ }^{1}$, Mirko Prosek ${ }^{1}$, Marko Volk ${ }^{2}$, Antonija Holcman ${ }^{3}$, Alenka Nemec Svete ${ }^{4}$ \\ ${ }^{1}$ Department for Food Chemistry, National Institute of Chemistry, Ljubljana, Slovenia \\ ${ }^{2}$ Faculty of Agriculture and Life Science, Hoce, Slovenia \\ ${ }^{3}$ Department of Animal Science, Biotechnical Faculty, Domzale, Slovenia \\ ${ }^{4}$ Small Animal Clinic, Veterinary Faculty, University of Ljubljana, Ljubljana, Slovenia \\ Email: andrej.smidovnik@ki.si
}

Received 17 October 2012; revised 24 November 2012; accepted 3 December 2012

\begin{abstract}
Antioxidants in the body are in balance, and form a network that protects living organisms against oxidative stress. To prove this hypothesis, we developed suitable methods for assessing the amount of antioxidants and their antioxidant activity in the chickens' plasma, which enable us to explain the overall antioxidant status of the animals during the controlled industrial raise. The effects of exogenous coenzyme $Q_{10}$, and $\alpha$-lipoic acid on the reduction of oxidative stress in the animal body were assessed. The physical and the health conditions of chickens during the raising period of 40 days were followed. The benefits of additives were estimated through the measured concentrations of selected low molecular weight antioxidants (coenzyme $Q_{10}, \alpha$-lipoic acid, $\alpha$-tocopherol, lutein and zeaxathin) and antioxidant enzymes (superoxide dismutase, glutathione reductase), cholesterol and glucose in plasma and measurements of total antioxidant capacity. Quantitative analyses of selected substances were done with different chromatographic, spectroscopic and electrometric methods. The addition of antioxidants has positive effects on the acts of antioxidant network.
\end{abstract}

Keywords: Chickens; Poultry; Coenzyme $\mathrm{Q}_{10} ; \alpha$-Lipoic Acid; Antioxidant Network; Fodder Additive

\section{INTRODUCTION}

The oxygen is a highly reactive molecule ready to damage living organisms $[1,2]$. In order to safely and effectively consume oxygen, organisms raise a complex network of enzymes, metabolites and molecules with antioxidant activities which prevent oxidative damage of cel- lular components. Active components terminate oxidation processes in the net by removing or quenching radical intermediates, and are capable of slowing or preventing the oxidation of other molecules [3].

Biological antioxidants may be classified into several defense groups; enzymes (catalase, peroxidase and superoxide dismutase), low molecular weight compounds (LMWA) with antioxidant activities based on a chain of chemical reactions, for instance glutathione, vitamin $\mathrm{C}$, vitamin E, $\alpha$-lipoic acid (ALA), coenzyme $\mathrm{Q}_{10}\left(\mathrm{CoQ}_{10}\right)$, urea etc., and the group of widespread natural plant pigments which protect biological samples mostly against ${ }^{1} \mathrm{O}_{2}$ - mediated damages by physical quenching. Such substances are carotenoids, for instance $\beta$-carotene, lycopene, lutein and zeaxanthin. The interactions between different antioxidants are a complex processes, with various metabolites and enzyme systems having synergistic and interdependent effects on one another. The amount of protection provided by any antioxidant therefore depends on its standard potentials $\mathrm{E}^{0}(\mathrm{~V})$, concentration, reactivity towards the particular reactive oxygen species, and the status of the antioxidants with which it may interacts (Table 1).

Until recently, scientists believed that each antioxidant worked separately, independently of the others. The results of research work performed at the Packer Lab at the University of California, Berkeley showed that there is a dynamic connection among certain key antioxidants. These special antioxidants work together and represent the dynamic defence of the organism. The expression antioxidant network was first used by Packer in his book The Antioxidant Miracle [4], where he stated that antioxidants do not act alone but are linked together into a net. The interaction of antioxidants had already been established before Packer, yet he was the first who outlined a concept of the mode of action of the antioxidant 
network including five molecules, $\mathrm{CoQ}_{10}$, ascorbic acid, tocopherol, glutathione and lipoic acid. According to his opinion no antioxidant acts alone, but is included in the net or supporting it, Figure 1.

Coenzyme $\mathrm{Q}_{10}$ or ubiquinone [5-7] is a lipid soluble substance consisting of quinone head and isoprenoid side chain. Apart from being a cofactor in the respiratory chain $\mathrm{CoQ}_{10}$ serves as an important antioxidant in mitochondria and lipid membranes [8,9]. In an organism the requirement for $\mathrm{CoQ}_{10}$ is usually fulfilled by biosynthesis, but in many cases administered substance to the diet is an important supplementary source [10]. $\mathrm{CoQ}_{10}$ is a lipophilic substance, and is usually converted into a more soluble formulation before it is added to various forms of food and fodder products. Our contribution in this field was a new originally prepared water soluble inclusion complex of $\mathrm{CoQ}_{10}$ with $\beta$-cyclodextrin $[11,12]$, which

Table 1. Some antioxidants and their standard potentials $E^{0}(V)$, which participate in formation of antioxidant network [38,39].

\begin{tabular}{|c|c|c|c|}
\hline $\mathbf{E}^{0}(\mathbf{V})$ & Substance & Product & Function \\
\hline-0.320 & Dihydrolipoic acid & Lipoic acid & Cofactor \\
\hline-0.317 & Riboflavin & Riboflavin • & Vitamin B2 \\
\hline-0.315 & $\mathbf{N A D}^{+}+\mathbf{H}^{+}+2 \mathrm{e}^{-}$ & NADH & Cofactor \\
\hline-0.240 & GSH (glutathione) & GSSG & Antioxidant \\
\hline-0.220 & $\mathrm{FAD}+2 \mathrm{H}^{+}+2 \mathrm{e}^{-}$ & $\mathrm{FADH}_{2}$ & Cofactor \\
\hline-0.220 & Ubiquinone & Ubisemiquinone & Coenzyme \\
\hline-0.160 & $\mathrm{O}_{2}$ & $\mathrm{O}_{2}^{\bullet}-$ & Superoxide \\
\hline$-\mathbf{0 . 0 3 8}$ & Ubiquinone & Ubiquinol & Coenzyme \\
\hline 0.030 & fumarate & Succinate & Cofactor \\
\hline $\begin{array}{c}0.077- \\
0.385\end{array}$ & Cyto b,c1,c,a,a3 & Cytochrome & Carrier \\
\hline 0.190 & Ubisemiquinone & Ubiquinol & Coenzyme \\
\hline 0.282 & Ascorbate & Ascorbyl & Vitamin C \\
\hline 0.407 & Quercetin & Adequate radical & $\begin{array}{c}\text { Plant } \\
\text { antioxidant }\end{array}$ \\
\hline 0.450 & Lutein & Adequate radical & $\begin{array}{c}\text { Plant } \\
\text { antioxidant }\end{array}$ \\
\hline 0.457 & Catechin & Adequate radical & $\begin{array}{c}\text { Plant } \\
\text { antioxidant }\end{array}$ \\
\hline 0.475 & Epigallocatechin & Gallat & $\begin{array}{c}\text { Plant } \\
\text { antioxidant }\end{array}$ \\
\hline 0.480 & Tocopherol & Tocopheroxyl & Vitamin E \\
\hline 0.513 & Rutin & Adequate radical & $\begin{array}{c}\text { Plant } \\
\text { antioxidant }\end{array}$ \\
\hline 0.590 & Urea & Adequate radical & Antioxidant \\
\hline 0.815 & $1 / 2 \mathrm{O}_{2}+2 \mathrm{H}^{+}+2 \mathrm{e}^{-}$ & $\mathrm{H}_{2} \mathrm{O}$ & Water \\
\hline 1.000 & peroxyl & $\mathrm{LOO}^{\bullet}$ & Radical \\
\hline 1.600 & alkoxyl & $\mathrm{LO}^{\bullet}$ & Radical \\
\hline 2.300 & hydroxyl & $\mathrm{OH}^{\bullet}$ & Radical \\
\hline
\end{tabular}

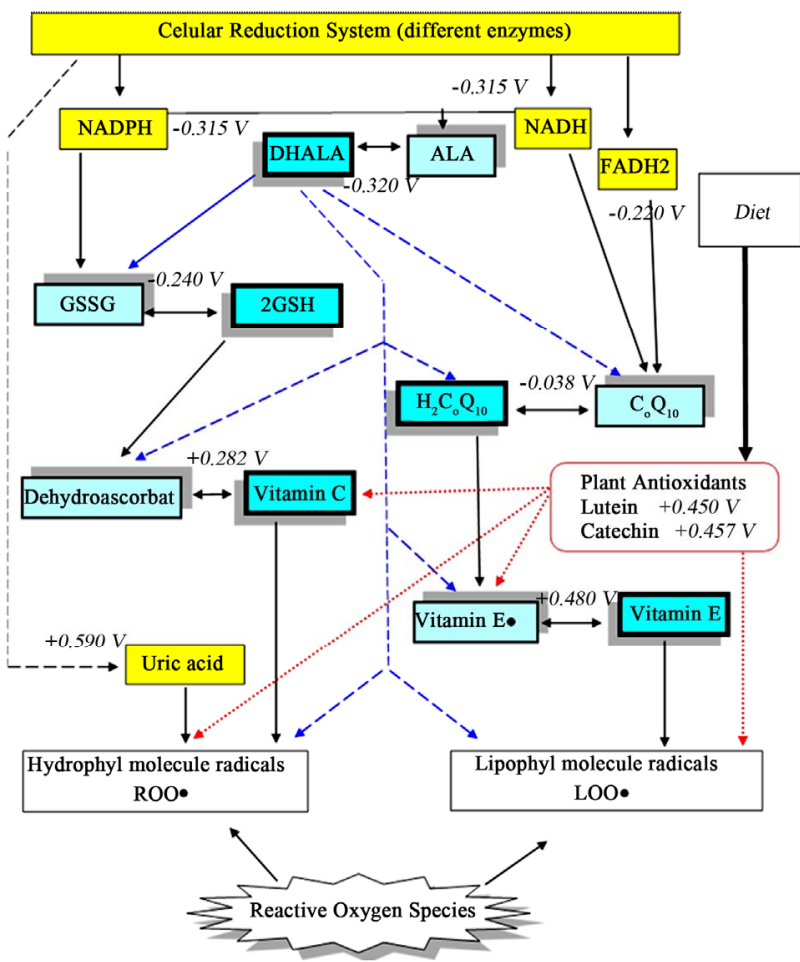

Figure 1. Chain structure of synergistic effect of five LMWA in chicken plasma, and standard potentials of some plant antioxidants, for instance carotenoids and catechins.

showed advantageous applicability, better enteric absorption, and bioavailability [13].

Alfa lipoic acid (ALA) is a yellow solid organosulfur compound [14]. Structurally it exists as a R+lipoic acid, $\mathrm{S}$-lipoic acid and as a racemic mixture R/S-lipoic acid. RLA exists in nature and is essential for life and aerobic metabolism. All forms can be reduced to dihydrolipoic acid with tissue specific or stereo selective reactions. ALA was recognized to have antioxidant potential in 1959 but it took more than 40 years to gain significant public attention and application in maintaining or restoring human health. ALA is presented in almost all foods, like animal kidney, heart, liver, spinach, and broccoli, however in very low concentration and as lipoyllisine. ALA is the rate-limiting factor for the production of acetyl coenzyme A. It is the generator of intracellular glutathione, which is the most efficient intracellular antioxidant and is a very efficient free radical scavenger, which removes many inflammatory products that interfere with normal organ regeneration. In addition ALA regenerates several antioxidants taking the active part in antioxidant network to scavenge the free radicals, like vitamin $\mathrm{C}$, vitamin $\mathrm{E}, \mathrm{CoQ}_{10}$ [14-16]. All ALA supplements are chemically synthesized because the naturally occurring lipoic acid is always covalently bounded and is not directly available from dietary sources. 
Our research work concerning industrial poultry farming pointed out that chickens and hens may be very suitable subjects for scientific estimation of the protective effect of LMWA in an antioxidant network. Previous studies were done mostly on rats and mice, where $\mathrm{CoQ}_{9}$ is the predominant homolog. In our experiments we selected chickens and hens, which major homolog is $\mathrm{CoQ}_{10}$ similar to human and animals with longer life time.

In the first part of our work we studied the accumulation of administered $\mathrm{CoQ}_{10}$ in particular parts of chicken body and the quality of prepared chicken products from the fortified meat and organs. The highest increase of $\mathrm{CoQ}_{10}$ concentration was observed in chicken breast cells after 40 days of feeding with $\mathrm{CoQ}_{10}$. Fractionation of chicken breast cells showed, that exogenous $\mathrm{CoQ}_{10}$ was mainly incorporated into cell membranes and not in mitochondria. This confirmed our hypothesis that $\mathrm{CoQ}_{10}$ added in chicken tissues acts mostly as an antioxidant [17]. From these results we concluded that $\mathrm{CoQ}_{10}$ in young chickens has an important role as an antioxidant in chicken plasma and in chicken tissues $[17,18]$.

In the second part of our work-analytical results presented in this paper, we evaluated the effects of $\mathrm{CoQ}_{10}$ and ALA on a minimization of the oxidative stress during the raise. The positive effects of exogenous $\mathrm{CoQ}_{10}$ and ALA have been described in many papers [7, 15,19-22], but only a few studies have assessed the effect on non-laboratory animals such as chickens and hens on farms [23-26].

Together with the Perutnina Ptuj d.d., Faculty of agriculture and life science from University of Maribor, and Biotechnical faculty from University of Ljubljana, we prepared a research project in which the health and plasma antioxidant status of broiler chickens during the controlled experimental and industrial raise was studied. The effects of supplemented $\mathrm{CoQ}_{10}$, and ALA and the combination of both substances on the reduction of oxidative stress and regeneration of other antioxidants in the animal body were assessed. The benefits of applied additives were estimated through the measured concentrations of selected LMWA ( $\mathrm{CoQ}_{10}, \mathrm{ALA}, \alpha$-tocopherol), enzyme antioxidant activities (superoxide dismutase (SOD), glutathione reductase (GPx) and total antioxidant capacity (TAC)), cholesterol and glucose. Concentration levels were measured with the intention to find synergistic effects and possibly confirm the presence of "an antioxidant network" in plasma.

\section{MATERIALS AND METHODS}

\subsection{Experimental Design}

Animals were divided into four treatment groups: three test groups $\left(\mathrm{G}_{\mathrm{CoQ}_{10}}, \mathrm{G}_{\mathrm{ALA}}, \mathrm{G}_{\mathrm{CoQ}_{10} \& \mathrm{ALA}}\right)$ with 50 animals (25 male, 25 female) and a control group $\left(\mathrm{G}_{\mathrm{C}}\right)$ with 200 animals (100 male, and 100 female). Each group was placed in separate stable. Tests were done in optimal breeding and healthy conditions. Animals in all groups were supplied with the same basic food. The flow chart of experimental procedure is presented in Figure 2.

Chicken fodders BRO-S and BRO-F1 were prepared according to the standard Ross 308 fodder specifications. In test group $\left(\mathrm{G}_{\mathrm{CoQ}_{10}}\right)$ the standard fodder was fortified with $40 \mathrm{mg} \mathrm{CoQ}_{10}$ per $\mathrm{kg}$, in test group $\left(\mathrm{G}_{\mathrm{ALA}}\right)$ it was fortified with $400 \mathrm{mg}$ of ALA per $\mathrm{kg}$, and in test group $\left(\mathrm{G}_{\mathrm{CoQ}_{10} \& \mathrm{ALA}}\right)$ the fodder with $40 \mathrm{mg} \mathrm{CoQ}_{10}$ and $400 \mathrm{mg}$ ALA per $\mathrm{kg}$ of BRO-F1 was prepared. The required amount of $\mathrm{CoQ}_{10}$ was provided as the water soluble additive originally synthesized in our laboratory by in-capsulation of $\mathrm{CoQ}_{10}$ into corn dextrin. The additive was commercially named AmilQ. The applied food grade ALA and raw $\mathrm{CoQ}_{10}$ were purchased from Linyi Tianliheng Trade Co (China).

Test groups started to receive the supplemented diet on day 14 and were fed for a period of 26 days. Concentrations of supplemented $\mathrm{CoQ}_{10}$ and ALA were calculated from feed instruction tables so that each chicken received an average of approximately $5 \mathrm{mg}$ of $\mathrm{CoQ}_{10}$ and (or) $50 \mathrm{mg}$ of ALA per $\mathrm{kg}$ of animal weight

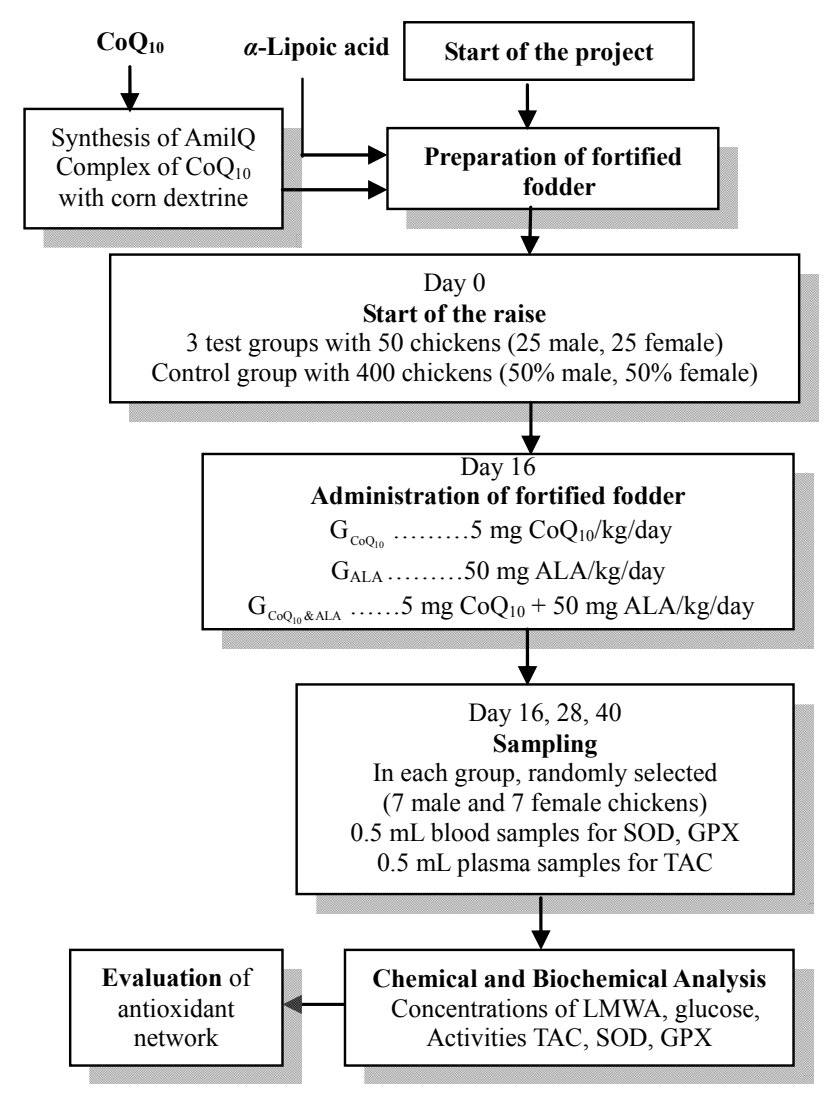

Figure 2. Experimental design. 
per day. During the 41-day pilot raise, all animals were treated under identical environmental and growing conditions. Health, appearance and behavior of each animal were recorded. The control group was raised and controlled under the same conditions but without fortified fodder.

During the raise blood samples were taken three times (on day 16, 28, and 40). In each group 7 male and 7 female animals were randomly selected and up to $2 \mathrm{ml}$ of blood were taken from vene cutaneae ulnaris. One part of the blood sample $(0.5 \mathrm{~mL})$ was stored for biochemical analysis (SOD, GPx) and the rest of the blood (up to 1.5 $\mathrm{mL}$ ) was used for plasma sample prepared for chemical analysis and TAS. Plasma end blood samples were stored in cool storage of $-80^{\circ} \mathrm{C}$ until the start of analyses.

In order to reduce the number of analysis plasma samples were pooled. Three plasma samples in each group (male and female separately) were randomly pooled into a "big" sample. Four pooled samples were prepared in the control group and in each of the test groups. Pooled samples were analyzed in two replicates. Biochemical parameters were measured with multi-channel analyzers and in this case collected blood samples were analyzed individually, for each animal, and the mean values were reported.

\subsection{Materials and Methods}

\subsubsection{Chemicals}

Methanol, ethanol, 2-propanol, 1,4-dioxane, acetonitrile, hexane, perchloric acid and acetic acid (LC grade) were supplied by Merck (Darmstadt, Germany). Carbohydrate standards (D-glucose, D-lactulose, D-mannitol), CoQ ${ }_{10}$, and $\alpha$-tocopherol standards were purchased from Sigma Aldrich (Steinheim, Germany). $\beta$-Cyclodextrin (food grade) was supplied by $\mathrm{Xi}^{\prime}$ an Hong Chang Pharmaceuticals Co. (China), $\mathrm{CoQ}_{10}$ and ALA (pharmaceuticals grade) was obtained from Linyi Tianliheng Trade Co (China) and Lutein (food grade powder) from Shaanxi Sciphar Biotechnology Co., China.

Deionized (DI) water with a resistivity of $18.2 \mathrm{M} \Omega \mathrm{cm}$ or greater was obtained from an Aqua Solutions (Jasper, USA) water purification system.

\subsubsection{Experimental Procedures}

Quantitative analyses of selected substances were done with different chromatographic, spectroscopic and electrometric methods. Concentrations of $\mathrm{CoQ}_{10}$ and lipoic acid were measured quantitatively using HPLC-APCIMS methods, $\alpha$-tocopherol was measured with HPLC and fluorescence detector, lutein and zeaxanthin with HPLC and UV detector, sugars were evaluated with ion chromatography (IC) combined with pulsed amperometric detection (PAD) and ESI-MS/MS detection. Cho- lesterol was measured with HPLC-MS and quantitative HPTLC. All methods were originally developed and validated in our laboratory.

\subsubsection{Quantitative Determination of Glucose}

Glucose levels were quantified with Dionex ICS3000 liquid chromatograph (Sunnyvale, CA) equipped with EG eluent generator and Electrochemical Detector. Separation was performed with a strong anion-exchange stationary phase Dionex CarboPac PA10 analytical column $(2 \mathrm{~mm} \times 250 \mathrm{~mm})$. Eluted carbohydrates were simultaneously quantified with Sciex QTRAP LC/MS/ MS system from Applied Biosystems/MDS (Sciex Concord, ON, Canada). Determination of glucose was carried out in Q1 MS scanning mode in the mass range from 150 to $200 \mathrm{~m} / \mathrm{z}$. A glucose quasi-molecular ion was formed with the added lithium ion $[180+7]^{+}$in positive ESI-MS ionization mode.

Plasma concentration was additionally confirmed with PAD, using standard four step potential waveform and originally developed two step potential waveform for quantitative determination of glucose in plasma samples [27].

\subsubsection{Quantitative Determination of $\mathrm{CoQ}_{10}$}

Before the analysis plasma samples stored at $-80^{\circ} \mathrm{C}$ were thawed in water bath at temperature $35^{\circ} \mathrm{C}-39^{\circ} \mathrm{C}$. Exactly $100 \mu \mathrm{L}$ of plasma sample was transferred into the $4 \mathrm{~mL}$ plastic vials and $100 \mu \mathrm{L}$ of para-benzoquinone $(0.4$ $\mathrm{mg} / \mathrm{ml}$ in 1-propanol) was added. Mixture was vortexed for 30 seconds and then set aside for the next 15 minutes. In this time para-benzoquinone oxidized the reduced form of $\mathrm{CoQ}_{10}$. Additionaly, $400 \mu \mathrm{L}$ of 1-propanol was added and solution was vortexed for 2 minutes followed by centrifugation for $4 \mathrm{~min}$ at $10.000 \mathrm{~g}$ on a tabletop centrifuge (Centrifuge Kendro Lab. Products, Heraeus, Biofuge, Stratos) to remove proteins. The $100 \mu \mathrm{L}$ aliquot of supernatant was diluted into a $5-\mathrm{mL}$ volumetric flask and analyzed with a HPLC-APCI-MS method [28].

Quantitative analyses of $\mathrm{CoQ}_{10}$ were done with Surveyor HPLC system (Thermo Electron corporation, San Jose, CA, USA), equipped with Hypersil Gold column $1.9 \mu \mathrm{m}(50 \mathrm{~mm} \times 2.1 \mathrm{~mm})$ with $3 \mu \mathrm{m}$ (Thermo Scientific (Runcorn, GB). Separated substances were detected with Finnigan-LCQ mass detector (Finnigan MAT, San Jose, CA, USA). The mobile phases used for gradient separation were: (A) a mixture of ethanol, methanol, 1,4-dioxan and acetic acid (65:30:5:0.1, v/v/v/v); and (B) 100\% acetonitrile. The initial conditions were $12 \% \mathrm{~A}$ and $88 \%$ B. Mobile phase A was changed linearly and after 3 minutes reached $95 \%$ A. For next 3 min it was held at 95\%. After that the HPLC system reverted immediately to the initial conditions for $2 \mathrm{~min}$. At the flow rate of 0.5 $\mathrm{mL} / \mathrm{min}$ and column temperature of $35^{\circ} \mathrm{C}$ the retention 
time of $\mathrm{CoQ}_{10}$ was $4.7 \pm 0.5 \mathrm{~min}$. Identification and quantification of $\mathrm{CoQ}_{10}$ by MS in positive APCI ionization mode were done. Ionization discharge voltage was $6.0 \mathrm{kV}$, discharge current $5.0 \mu \mathrm{A}$, and source temperature $450^{\circ} \mathrm{C}$. Capillary voltage was $3.0 \mathrm{~V}$, tube lens offset was $-5.0 \mathrm{~V}$, capillary temperature was $250^{\circ} \mathrm{C}$, sheath gas pressure was $0.2 \mathrm{MPa}$, auxiliary gas flow was $1.7 \mathrm{~L} / \mathrm{min}$, and injection time $5.0 \mathrm{~ms}$. Chromatograms were obtained in SIM mode. Molecular mass $(\mathrm{M}+\mathrm{H})^{+} \mathrm{m} / \mathrm{z} 863.4 \pm 0.5$ was used for quantitative determination of $\mathrm{CoQ}_{10}$. It was possible to quantify cholesterol $(\mathrm{M}+\mathrm{H})^{+} \mathrm{m} / \mathrm{z} 386 \pm 1$ in the same run as $\mathrm{CoQ}_{10}$. Data were processed with Xcalibur 1.3. Software pack.

\subsubsection{Quantitative Determination of $\alpha$-Tocopherol}

Plasma samples stored at $-80^{\circ} \mathrm{C}$ were thawed in water bath at temperature $35^{\circ} \mathrm{C}-39^{\circ} \mathrm{C}$. Exactly $200 \mu \mathrm{L}$ of plasma sample was transferred into the $4 \mathrm{~mL}$ plastic vial and $200 \mu \mathrm{L}$ of ethanol was added and solution was vortexed for 0.5 minute. In the next step $400 \mu \mathrm{L}$ of hexane was added and vial was vortexed for another 0.5 minute followed by centrifugation for $2 \mathrm{~min}$ at $10.000 \mathrm{~g}$ on a tabletop centrifuge (Centrifuge Kendro Lab. Products, Heraeus, Biofuge, Stratos). The $20 \mu \mathrm{L}$ of supernatant was injected into a HPLC (Thermo Electron Corporation, San Jose, CA, USA). Separation was done with Phenomex LiChrosorb column $5 \mu \mathrm{m}(125 \mathrm{~mm} \times 4 \mathrm{~mm})$, the mobile phases was $1 \%$ 2-propanol in hexane and the flow rate was $1.0 \mathrm{~mL} / \mathrm{min}$. Identification and quantification of tocopherols were done with Hitachi F-1000 fluorescence detector (Hitachi Ltd, Tokyo, Japan). The excitation wavelength was $295 \mathrm{~nm}$ and the cut-off wavelength was $380 \mathrm{~nm}$. The linear calibration curve was prepared in the range between $0.2 \mu \mathrm{g} / \mathrm{mL}$ do $20 \mu \mathrm{g} / \mathrm{mL}$ [29].

\subsubsection{Quantitative Determination of Lipoic Acid}

Plasma samples were thawed in water bath at temperature $35^{\circ} \mathrm{C}-39^{\circ} \mathrm{C}$. Exactly $300 \mu \mathrm{L}$ of plasma sample was transferred into the $4 \mathrm{~mL}$ plastic vial and $600 \mu \mathrm{L}$ of acetonitrile added and solution was vortexed for 0.5 minute. The vial was transferred into a cooled tabletop centrifuge (Centrifuge Kendro Lab. Products, Heraeus, Biofuge, Stratos) at $4^{\circ} \mathrm{C}$ and centrifuged for 10 minutes at 10.000 g. Supernatant was analyzed with HPLC system combined with the Sciex QTRAP LC/MS/MS system equipped with TurboIonSprayTM source. Separation was done with Hypersil Gold column $1.9 \mu \mathrm{m}(50 \mathrm{~mm} \times 2.1$ $\mathrm{mm}$ ) equipped with adequate $3 \mu \mathrm{m}$ precolumn Thermo Scientific (Runcorn, GB). The mobile phases were 1\% 2-propanol in hexane and the flow rate was $1.0 \mathrm{~mL} / \mathrm{min}$. The method followed the procedure from the literature [30].

\subsubsection{Quantitative Determination of Lutein and Zeaxanthin}

Chicken plasma samples $(200 \mu \mathrm{L})$ were pipetted into centrifuge tubes and $400 \mu \mathrm{L}$ of hexane: 1-propanol, (1:1, $\mathrm{v} / \mathrm{v})$ was added. The content was vortexed for 1 minute. The vial was transferred into a tabletop centrifuge (Centrifuge Kendro Lab. Products, Heraeus, Biofuge, Stratos) and centrifuged for 10 minutes at $10.000 \mathrm{~g}$. The upper layer was transferred into a vial and analyzed with HPLC with UV detector. Calibration curve with six standard solutions from 0.05 to $50 \mu \mathrm{g} / \mathrm{mL}$ of all-translutein was prepared.

Separation was done at room temperature $25^{\circ} \mathrm{C}$ on Luna $3 \mu \mathrm{C} 18(2) 100 \mathrm{~A}$ column, $100 \times 3.0 \mathrm{~mm}$, with 3 $\mu \mathrm{m}$ particle size (Torrance, California, USA), equipped with a Phenomenex C18 guard column (Torrance, California, USA). Flow rate was $0.5 \mathrm{ml} / \mathrm{min}$ and injection volume was $20 \mu$. The mobile phases used for gradient separation were: methanol (solvent A), 1-propanol (solvent $\mathrm{B}$ ) and water (solvent $\mathrm{C}$ ). Gradient: $\mathrm{t}=0 \mathrm{~min}, 85 \%$ A, $15 \% \mathrm{C} ; \mathrm{t}=1 \mathrm{~min}, 85 \% \mathrm{~A}, 15 \% \mathrm{C} ; \mathrm{t}=5 \mathrm{~min}, 40 \% \mathrm{~A}$, $60 \% \mathrm{~B} ; \mathrm{t}=10 \mathrm{~min}, 40 \% \mathrm{~A}, 60 \% \mathrm{~B} ; \mathrm{t}=11 \mathrm{~min}, 5 \% \mathrm{~A}$, $15 \% \mathrm{C} ; \mathrm{t}=16 \mathrm{~min}, 85 \% \mathrm{~A}, 15 \% \mathrm{C}$. Co-eluted ubiquinone was analyzed in UV range at $280 \mathrm{~nm}$ and lutein and zeaxanthine, were eluted together and measured in VIS range at $450 \mathrm{~nm}$. ChromQuest 4.2 was used for the evaluation of the data.

\subsubsection{GPx, SOD and Total Antioxidant Capacity}

The methodology of Paglia and Valentine (1967) was used for measurements of GPx [31]. Measurements were done with colorimetric method $(340 \mathrm{~nm})$ with biochemical analyzer RX Daytona (RANDOX, Crumlin, UK) following the instructions of the kit manufacturer. The decrease in absorbance at $340 \mathrm{~nm}$ was directly proportional to the GPx concentration. The GPx activity was given in units related to gram of hemoglobin $(\mathrm{U} / \mathrm{g} \mathrm{Hgb})$ measured with Technicon $\mathrm{H}^{*} 1$ (SIEMENS, Munchen, D) automated hematology analyzer.

The activity of Superoxide dismutase (SOD) was measured with sensitive assay kit RANSOD (RANDOX, Crumlin, UK) according to the method of McCord and Fridovich (1969), containing the necessary reagents for convenient measurement of activity by colorimetric method at $510 \mathrm{~nm}$, using the Randox RX Daytona biochemical analyzer [32]. The activity of SOD was given in units related to the amount (gram) of hemoglobin (U/gHgb) measured with Technicon $\mathrm{H}^{* 1}$ automated hematology analyzer.

TAC (Total Antioxidant Capacity) was measured at 600 $\mathrm{nm}$ using reagent kit for TAS (Total Antioxidant Status, RANDOX, Crumlin, GB) on the automatic Randox RX Daytona biochemical analyzer. The method is based on the ability of antioxidant molecules to quench the long-lived 
$\mathrm{ABTS}^{\circ+}$, a blue-green chromophore with characteristic absorption at $734 \mathrm{~nm}$, compared with that of Trolox, (6hydroxy-2,5,7,8-tetramethylchroman-2-carboxylic acid) a water-soluble vitamin $\mathrm{E}$ analog. The amount of antioxidants was measured with the drop of absorbance at 600 $\mathrm{nm}$ (after 3 minutes). Results were expressed as mmol of Trolox per L of plasma.

\subsubsection{Statistical Analysis}

From data pre-arranged with Microsoft Excel 2007, we calculated basic statistical parameters (mean and standard deviation) using SAS/STAT (SAS Software, 1999).

\section{RESULTS AND DISCUSSION}

During the raise plasma samples were collected three times (on day 16, 28, 40) from four different groups $\left(G_{C}\right.$, $\left.\mathrm{G}_{\mathrm{COQ}_{10}}, \mathrm{G}_{\mathrm{ALA}}, \mathrm{G}_{\mathrm{COQ}_{10} \& \mathrm{ALA}}\right)$ and several parameters were monitored and recorded. In the following figures and text we shall describe observed differences in concentrations of measured substances and variations in enzyme activeties.

\subsection{Quantitative Determination of Glucose Plasma Levels}

Harms produced by a protracted oxidative stress are somewhat connected with the carbohydrates, and that was the reason to select also the concentration of glucose as a parameter in our study. Several different analytical techniques from TLC to IC-PAD and IC-MS were used for quantitative determination [33,34]. Collected results (Table 2) show that normal concentrations of glucose in chicken plasma increased during the 41 day raise.

Table 2. Influence of added $\mathrm{CoQ}_{10}$, lipoic acid and combination of $\mathrm{CoQ}_{10}$ and lipoic acid in chicken feed on glucose and cholesterol concentration in plasma in $\mathrm{G}_{\mathrm{C}}, \mathrm{G}_{\mathrm{CoQ}_{10}}, \mathrm{G}_{\mathrm{ALA}}$, $\mathrm{G}_{\mathrm{CoQ}_{10} \& A L A}$ groups during chicken raising; $\left(\mathrm{n}\left(\mathrm{G}_{\mathrm{C}}\right)=100, \mathrm{n}\right.$ $\left(\mathrm{G}_{\mathrm{CoQ}_{10}}, \mathrm{G}_{\mathrm{ALA}}, \mathrm{G}_{\mathrm{CoQ}_{10} \& \mathrm{ALA}}\right)=50, \bar{x}=$ mean, $\mathrm{sd}=$ standard deviation).

\begin{tabular}{ccccc}
\hline \multirow{2}{*}{$\begin{array}{c}\text { Day of } \\
\text { sampling/group }\end{array}$} & \multicolumn{5}{c}{ glucose (mmol/L) $\bar{x} \pm \mathbf{~ s d}$} \\
\cline { 2 - 6 } & $\mathrm{G}_{\mathrm{C}}$ & $\mathrm{G}_{\mathrm{CoQ}_{10}}$ & $\mathrm{G}_{\mathrm{ALA}}$ & $\mathrm{G}_{\mathrm{COQ}_{10} \& \mathrm{ALA}}$ \\
\hline $\mathbf{1 6}$ & $20.2 \pm 1.65$ & $25.8 \pm 0.56$ & $29.6 \pm 1.11$ & $25.1 \pm 0.77$ \\
$\mathbf{2 8}$ & $25.2 \pm 3.06$ & $27.2 \pm 1.33$ & $30.7 \pm 1.14$ & $27.3 \pm 0.20$ \\
$\mathbf{4 0}$ & $24.0 \pm 0.78$ & $27.5 \pm 0.54$ & $27.8 \pm 1.39$ & $25.6 \pm 0.34$ \\
\hline $\begin{array}{c}\text { Day of } \\
\text { sampling/group }\end{array}$ & $\mathrm{G}_{\mathrm{C}}$ & $\mathrm{G}_{\mathrm{CoQ}_{10}}$ & $\mathrm{G}_{\mathrm{ALA}}$ & $\mathrm{G}_{\mathrm{COQ}_{10} \& \mathrm{ALA}}$ \\
\hline $\mathbf{1 6}$ & $412.6 \pm 21.2$ & $451.5 \pm 7.8$ & $398.2 \pm 99.9$ & $368.6 \pm 44.7$ \\
$\mathbf{2 8}$ & $226.4 \pm 29.3$ & $273.0 \pm 47.5$ & $228.7 \pm 30.2$ & $249.7 \pm 26.8$ \\
$\mathbf{4 0}$ & $203.8 \pm 9.6$ & $199.9 \pm 25.6$ & $191.6 \pm 33.3$ & $199.2 \pm 40.2$ \\
\hline
\end{tabular}

In the control group the final concentration, measured on day 40 was $20 \%$ higher than the starting concentration measured on day 16. In test groups, which administered fortified fodder the increase in glucose level in plasma was smaller than in the control group. In the case of administered $\mathrm{CoQ}_{10}$ the final concentration was $7 \%$ higher, and in the case of fodder with combination ALA and $\mathrm{CoQ}_{10}$ the final concentration was only $2 \%$ higher than on day 16 . The rewarding result was obtained with pure ALA, where the final concentration was even $6 \%$ lower than on day 16. Our findings are comparable to previously published data [14] and show that exogenous $\mathrm{CoQ}_{10}$ and ALA as the food additives may reduce the plasma level of glucose. Our result confirms a beneficial effect of ALA, described in papers taking an interest in the diabetes.

\subsection{Quantitative Determination of Total $\mathrm{CoQ}_{10}$}

CoQ10 exists in nature and in the body in two forms: the oxidized form (ubiquinone) and reduced form (ubiquinol). Reverse chromatography with electrochemical detector was mostly used for quantitative determination [35]. The reduced form of $\mathrm{CoQ}_{10}$ in plasma can be stable at least 48 hour storage at $-80^{\circ} \mathrm{C}$ [36], and therefore we decided to measure the total concentration of $\mathrm{CoQ}_{10}$ in their oxidized form. As can be seen, the concentration of $\mathrm{CoQ}_{10}$ in plasma increased noticeably in all groups during the raise (Table 3 ).

In the control group the concentration of total $\mathrm{CoQ}_{10}$ in plasma increased for nearly $100 \%$ from starting concentration of $0.5 \mathrm{mg} / \mathrm{L}$ to nearly $1.0 \mathrm{mg} / \mathrm{L}$ at the end. In the test group feed with ALA the concentration of $\mathrm{CoQ}_{10}$ increased from $0.5 \mathrm{mg} / \mathrm{L}$ to $1.3 \mathrm{mg} / \mathrm{L}$ and the final plasma concentration was $0.3 \mathrm{mg} / \mathrm{L}$ higher than in the control group. Similar results were obtained in the $\mathrm{G}_{\mathrm{CoQ10} \& A L A}$ supplemented group. Concentration of $\mathrm{CoQ}_{10}$ increased nearly 3 times, to final concentration $1.5 \mathrm{mg} / \mathrm{L}$. The highest concentration was recorded in the test group using the fodder fortified with $\mathrm{CoQ}_{10}$. The final concentration was $360 \%$ higher than starting one, from standard value about $0.5 \mathrm{mg} / \mathrm{L}$ to nearly $1.8 \mathrm{mg} / \mathrm{L}$.

Very high increase of total $\mathrm{CoQ}_{10}$ plasma concentration in test group supplemented with ALA was not expected, and it is a certain surprise. In our opinion the increased concentration is a result of in-line protection of $\mathrm{CoQ}_{10}$ due to the electrochemical potential of ALA. It is assumed, that ALA stabilizes the endogenous $\mathrm{CoQ}_{10}$, which is carried with appoproteins into the blood. Additional research will be necessary to confirm this thesis.

The final concentration in the group foddered with $\mathrm{CoQ}_{10}$ and ALA is unexpectedly lower than in the $\mathrm{GCoQ}_{10}$ group. Our explanation is that in the case of higher concentration of both substances the synergistic 
effect of LWMA in the antioxidant network takes place and $\mathrm{CoQ}_{10}$ is eliminated from the blood through the degradation of $\mathrm{CoQ}_{10}$ in liver. Liver functions are kept on a high working level and liver is not forced to produce new $\mathrm{CoQ}_{10}$, because the exogenous coenzyme keeps enough high concentration.

\subsection{Quantitative Determination of $\alpha$-Lipoic Acid}

Lipoic acid can be found in the body as free and protein bounded form [15]. Concentrations of free ALA in plasma and animal tissues are very low. In chicken plasma concentration of ALA is in general, up to hundred times lover then adequate concentrations of $\mathrm{CoQ}_{10}$ and was in the $\mu \mathrm{g} / \mathrm{L}$ range (Table 3). The reason for low levels of free ALA is very quick formation of protein-bound lipoic acid in plasma [14]. The bioavailability studies showed that concentration of ALA in plasma fall in relatively short time (40 minutes) after

Table 3. Influence of added $\mathrm{CoQ}_{10}$, lipoic acid and combination of $\mathrm{CoQ}_{10}$ and lipoic acid in chicken feed on $\mathrm{CoQ}_{10}$ concentration $(\mathrm{mg} / \mathrm{L})$, lipoic acid concentration $\left(\times 10^{-1} \mathrm{mg} / \mathrm{L}\right)$, $\alpha$-tocopherol concentration $(\mathrm{mg} / \mathrm{L})$ and lutein and zeaxanthin $(\mathrm{mg} / \mathrm{L})$ in plasma in groups $\left(\mathrm{G}_{\mathrm{C}}, \mathrm{G}_{\mathrm{CoQ}_{10}}, \mathrm{G}_{\mathrm{ALA}}, \mathrm{G}_{\mathrm{CoQ}_{10} \& \mathrm{ALA}}\right)$ during chicken raising; $\left(\mathrm{n}\left(\mathrm{G}_{\mathrm{C}}\right)=100, \mathrm{n}\left(\mathrm{G}_{\mathrm{CoQ} 10}, \mathrm{G}_{\mathrm{ALA}}\right.\right.$, $\left.\mathrm{G}_{\mathrm{CoQ}_{10} \& \mathrm{ALA}}\right)=50, \bar{x}=$ mean, $\mathrm{sd}=$ standard deviation.

\begin{tabular}{|c|c|c|c|c|}
\hline \multirow{2}{*}{$\begin{array}{c}\text { Day of } \\
\text { sampling/group }\end{array}$} & \multicolumn{4}{|c|}{$\mathrm{CoQ}_{10}(\mathrm{mg} / \mathrm{L}) \quad \bar{x} \pm \mathrm{sd}$} \\
\hline & $\mathrm{G}_{\mathrm{C}}$ & $\mathrm{G}_{\mathrm{CoQ}_{10}}$ & $\mathrm{G}_{\mathrm{ALA}}$ & $\mathrm{G}_{\mathrm{CoQ}_{10} \& \mathrm{ALA}}$ \\
\hline 16 & $0.46 \pm 0.06$ & $0.47 \pm 0.09$ & $0.46 \pm 0.09$ & $0.48 \pm 0.11$ \\
\hline 28 & $0.59 \pm 0.15$ & $0.84 \pm 0.33$ & $0.94 \pm 0.38$ & $0.70 \pm 0.15$ \\
\hline 40 & $0.92 \pm 0.26$ & $1.78 \pm 0.70$ & $1.34 \pm 0.13$ & $1.54 \pm 0.97$ \\
\hline \multirow{2}{*}{$\begin{array}{c}\text { Day of } \\
\text { sampling/group }\end{array}$} & \multicolumn{3}{|c|}{ lipoic acid $\left(\times 10^{-1} \mathrm{mg} / \mathrm{L}\right) \bar{x}$} & \pm sd \\
\hline & $\mathrm{G}_{\mathrm{C}}$ & $\mathrm{G}_{\mathrm{CoQ}_{10}}$ & $\mathrm{G}_{\mathrm{ALA}}$ & $\mathrm{G}_{\mathrm{CoQ}_{10} \& \mathrm{ALA}}$ \\
\hline 16 & $0.37 \pm 0.16$ & $0.51 \pm 0.16$ & $0.49 \pm 0.08$ & $0.54 \pm 0.03$ \\
\hline 28 & $0.14 \pm 0.01$ & $0.50 \pm 0.15$ & $7.79 \pm 0.70$ & $6.14 \pm 1.25$ \\
\hline 40 & $0.09 \pm 0.01$ & $0.27 \pm 0.02$ & $1.62 \pm 0.48$ & $0.76 \pm 0.35$ \\
\hline \multirow{2}{*}{$\begin{array}{c}\text { Day of } \\
\text { sampling/group }\end{array}$} & \multicolumn{4}{|c|}{$\alpha$-tocopherol (mg/L) $\bar{x} \pm$ sd } \\
\hline & $\mathrm{G}_{\mathrm{C}}$ & $\mathrm{G}_{\mathrm{CoQ}_{10}}$ & $\mathrm{G}_{\mathrm{ALA}}$ & $\mathrm{G}_{\mathrm{CoQ}_{10} \& \mathrm{ALA}}$ \\
\hline 16 & $8.74 \pm 0.59$ & $9.46 \pm 2.45$ & $9.00 \pm 2.45$ & $8.82 \pm 1.27$ \\
\hline 28 & $9.83 \pm 1.04$ & $13.93 \pm 1.71$ & $15.57 \pm 1.98$ & $10.94 \pm 0.87$ \\
\hline 40 & $12.97 \pm 0.94$ & $15.77 \pm 0.70$ & $17.70 \pm 0.24$ & $13.43 \pm 0.16$ \\
\hline \multirow{2}{*}{$\begin{array}{c}\text { Day of } \\
\text { sampling/group }\end{array}$} & \multicolumn{3}{|c|}{ lutein and zeaxanthin $(\mathrm{mg} / \mathrm{L})$} & $\bar{x} \pm \mathbf{s d}$ \\
\hline & $\mathrm{G}_{\mathrm{C}}$ & $\mathrm{G}_{\mathrm{CoQ}_{10}}$ & $\mathrm{G}_{\mathrm{ALA}}$ & $\mathrm{G}_{\mathrm{CoQ}_{10} \& \mathrm{ALA}}$ \\
\hline 16 & $22.28 \pm 1.75$ & $23.08 \pm 5.12$ & $24.78 \pm 7.90$ & $22.93 \pm 3.83$ \\
\hline 28 & $16.33 \pm 0.60$ & $16.43 \pm 2.87$ & $17.96 \pm 3.28$ & $16.26 \pm 3.78$ \\
\hline 40 & $15.74 \pm 2.47$ & $20.87 \pm 9.41$ & $21.51 \pm 8.34$ & $19.88 \pm 9.39$ \\
\hline
\end{tabular}

administration. In these circumstances the correct collection time of plasma samples may be crucial. Also in our analysis we observed some high unrealistic variations in the measured concentrations.

As we expected, measured concentrations of ALA in the control group and also in the test groups supplemented with $\mathrm{CoQ}_{10}$ were slightly lower at the end of the raise. It is known that concentrations of ALA are higher in young than in grown animals, and humans. When the fodder fortified with ALA was used the relative overall concentration increased significantly, however absolute concentration was still below mg/L. Also in this case the combination of $\mathrm{CoQ}_{10}$ and ALA was not very successful. Measured concentrations represent the free ALA, which has not yet been bound to a protein. Relatively lower concentration of ALA in the test group $\mathrm{G}_{\mathrm{CoQ}_{10} \text { \& ALA may }}$ be explained with interacting effects of both substances. ALA is a strong antioxidant with a possibility to protect $\mathrm{CoQ}_{10}$ due to its electrochemical potential. The same trick is used in commercially available reduced form of $\mathrm{CoQ}_{10} .30 \mathrm{mg}$ of $\mathrm{CoQ}_{10}(\mathrm{M}=865)$ and "only" $10 \mathrm{mg}$ of ALA $(M=206)$ are packed into the same capsule; however, the high molar concentration of ALA is needed to support the stability of reduced form of $\mathrm{CoQ}_{10}$ in the capsules.

\subsection{Quantitative Determination of $\alpha$-Tocopherol}

Vitamin E deficiency is associated with several diseases therefore the Vitamin E is normaly added in chicken feed. Only the $\alpha$-tocopherol was quantified due to its highest concentration in plasma.

Concentration of $\alpha$-tocopherol in chicken plasma increased during the raise and was nearly 50\% higher at the end than at the start of our experiment (Table 3 and Figure 3).

The same increase of $50 \%$ was recorded in test group fed with ALA and $\mathrm{CoQ}_{10}$. In the test group foddered with a food supplemented with the $\mathrm{CoQ}_{10}$ the final concentration was $60 \%$ higher and in the test group using fodder with ALA the final concentration was nearly $100 \%$ higher than the start concentration, Table 3. Our opinion is that increased concentration of $\alpha$-tocopherol in the test group fed with ALA is the result of its actions in antioxidant network. The very high reduction power and its mobility in lipophilic and hydrophilic medium can directly reduce $\alpha$-tocopherol and increase its concentration. The same direct access of administered antioxidant can be seen in the case of $\mathrm{CoQ}_{10}$ too. On the contrary, the results showed that the combination of two strong antioxidants; $\mathrm{CoQ}_{10}$, and ALA with different electrochemical potentials and different solubility is not so successful. The reduction of $\alpha$-tocopherol is done according to the control functions of normal antioxidant network. 




Figure 3. Relative changes of $\mathrm{E}$ vitamin concentrations in test groups fed with different fodder additives. Applied labels (-O-) control group, ( $\bigcirc-) \mathrm{CoQ}_{10}$, (一-) ALA, (- - - $) \mathrm{CoQ}_{10} \&$ ALA.

\subsection{Quantitative Determination of Lutein and Zeaxanthin}

The most prevalent carotenoids in the plasma of broilers are lutein and its structure isomer zeaxanthin. In our experiment we measured them in order to determine if supplemented $\mathrm{CoQ}_{10}$ and ALA with strong antioxidant properties had some impact on the plasma concentrations of carotenoids. Corn is an important natural ingredient in the chicken's fodder and the total contents of carotenoids may overcome $10 \mathrm{mg} / \mathrm{kg}$. In some circumstances they are the main carrier of antioxidant activities, but they are not a true member of an antioxidant network in an animal biological system [37]. The main difference is the way how they function. LMWA are reduced and oxidized reversibly to inhibit oxidizing species and are not destroyed in this process. While carotenoids function as singlet oxygen quencher. In this process the energy of the excited oxygen is transferred to the carotenoid molecules and is dissipated through surrounding solvent. In the physical quenching molecules are not destroyed and are used several times. When carotenoids reacts with free radicals in the presence of oxygen and are not strongly protected by some other antioxidants, for instance vitamin $\mathrm{E}$, their mission, which is normally not destructive, is transformed into suicidal peroxidation. The higher the concentration of oxygen or carotenoid the more devastating is the effect of auto-oxidation. The mechanisms of action of carotenoids regarding their antioxidant properties are much less understood than are the properties of "other" LWMA.

Due to expected increased antioxidant activity we decided to monitor the concentrations of lutein and zeax- anthin in plasma samples collected during the breeding period. In Table 3 the influence of added $\mathrm{CoQ}_{10}$, lipoic acid and combination of $\mathrm{CoQ}_{10}$ and lipoic acid in chicken feed on selected antioxidants in plasma of tested groups of chickens is presented. Obtained results are still informative, however if we want to know the real contribution of physical antioxidants and suicidal molecules in integral antioxidant system we have to carry out more experiments with different combinations of interesting molecules.

\subsection{Biochemical Analysis}

TAC is a biochemical parameter suitable for evaluating the overall antioxidant status of serum or plasma. According to our expectations the value of total antioxidant capacity in chicken plasma decrease during the raise, see Table 4.

The biggest decrease was recorded in control group, in which the final value was $20 \%$ lower than at the start. Smaller decrease was observed in the test group administered $\mathrm{CoQ}_{10}$. Even better result was obtained in the group foddered with a combination of ALA and $\mathrm{CoQ}_{10}$. A very good result was achieved in the case of the fodder fortified with lipoic acid. Our results show that fodder additives can significantly influence on TAC values in plasma. Furthermore, ALA exhibits the very high antioxidant potential in protection of animals

Table 4. Influence of added $\mathrm{CoQ}_{10}$, lipoic acid and combination $\mathrm{CoQ}_{10}$ and lipoic acid in chicken feed on TAC (mmol/L), SOD content $(\mathrm{U} / \mathrm{mL})$ and $\mathrm{GPx}$ content $(\mathrm{U} / \mathrm{mL})$ in plasma in $\mathrm{G}_{\mathrm{C}}$, $\mathrm{G}_{\mathrm{CoQ}_{10}}, \mathrm{G}_{\mathrm{ALA}}, \mathrm{G}_{\mathrm{CoQ}_{10} \& \mathrm{ALA}}$ groups during chicken raising; $\left(\mathrm{n}\left(\mathrm{G}_{\mathrm{C}}\right)=\right.$ $100, \mathrm{n}\left(\mathrm{G}_{\mathrm{CoQ}_{10}}, \mathrm{G}_{\mathrm{ALA}}, \mathrm{G}_{\mathrm{COQ}_{10} \& \mathrm{ALA}}\right)=50, \bar{x}=$ mean, $\mathrm{sd}=$ standard deviation).

\begin{tabular}{|c|c|c|c|c|}
\hline \multirow{2}{*}{$\begin{array}{c}\text { Day of } \\
\text { sampling/group }\end{array}$} & \multicolumn{4}{|c|}{ TAC $(\mathrm{mmol} / \mathrm{L}) \quad \bar{x} \pm \mathrm{sd}$} \\
\hline & $\mathrm{G}_{\mathrm{C}}$ & $\mathrm{G}_{\mathrm{CoQ}_{10}}$ & $\mathrm{G}_{\mathrm{ALA}}$ & $\mathrm{G}_{\mathrm{COQ}_{10} \& A L A}$ \\
\hline 16 & $0.90 \pm 0.15$ & $0.94 \pm 0.13$ & $0.93 \pm 0.10$ & $0.93 \pm 0.10$ \\
\hline 28 & $1.16 \pm 0.14$ & $1.14 \pm 0.12$ & $1.17 \pm 0.06$ & $1.17 \pm 0.19$ \\
\hline 40 & $1.00 \pm 0.34$ & $1.06 \pm 0.12$ & $1.16 \pm 0.14$ & $1.14 \pm 0.31$ \\
\hline \multirow{2}{*}{$\begin{array}{c}\text { Day of } \\
\text { sampling/group }\end{array}$} & \multicolumn{4}{|c|}{$\operatorname{SOD}(\mathbf{U} / \mathbf{m L}) \quad \bar{x} \quad \pm \mathbf{s d}$} \\
\hline & $\mathrm{G}_{\mathrm{C}}$ & $\mathrm{G}_{\mathrm{CoQ}_{10}}$ & $\mathrm{G}_{\mathrm{ALA}}$ & $\mathrm{G}_{\mathrm{CoQ}_{10} \& \mathrm{ALA}}$ \\
\hline 16 & $47.6 \pm 6.0$ & $46.2 \pm 4.0$ & $55.4 \pm 14.3$ & $58.5 \pm 12.2$ \\
\hline 28 & $49.9 \pm 9.0$ & $47.1 \pm 7.2$ & $49.2 \pm 10.1$ & $52.2 \pm 9.2$ \\
\hline 40 & $55.2 \pm 8,4$ & $43.3 \pm 7.8$ & $50.0 \pm 7.1$ & $55.0 \pm 9.5$ \\
\hline \multirow{2}{*}{$\begin{array}{c}\text { Day of } \\
\text { sampling/group }\end{array}$} & \multicolumn{4}{|c|}{$\begin{array}{lll}\text { GPx }(\mathrm{U} / \mathrm{mL}) & \bar{x} & \pm \mathbf{s d}\end{array}$} \\
\hline & $\mathrm{G}_{\mathrm{C}}$ & $\mathrm{G}_{\mathrm{CoQ}_{10}}$ & $\mathrm{G}_{\mathrm{ALA}}$ & $\mathrm{G}_{\mathrm{CoQ}_{10} \& \mathrm{ALA}}$ \\
\hline 16 & $18.69 \pm 2.77$ & $14.97 \pm 3.01$ & $18.07 \pm 1.66$ & $16.26 \pm 3.05$ \\
\hline 28 & $19.27 \pm 2.30$ & $18.57 \pm 3.78$ & $33.86 \pm 9.26$ & $19.89 \pm 2.04$ \\
\hline 40 & $22.20 \pm 2.66$ & $22.49 \pm 4.82$ & $36.61 \pm 7.60$ & $26.54 \pm 3.22$ \\
\hline
\end{tabular}


exposed to oxidative stress.

The GPx values increased during the experiment in all groups, but much higher increase was obtained in test groups using some fodder additive, the increase of control group was $20 \%$. Six times higher increase of $120 \%$ was recorded in ALA test group. Lower than expected increase was noticed in $\mathrm{G}_{\mathrm{CoQ}_{10}}$ and

$\mathrm{G}_{\mathrm{CoQ}_{10} \text { \& ALA }}$ groups. Measured values were about $60 \%$ higher than in control group (Table 4). Increased GPx activities may be connected with improved function of entire antioxidant network. Very high influence of ALA can be explained with high reactivity, movability and solubility of ALA in lipophilic and hydrophilic media and the lowest elec- trochemical potential of $-0.320 \mathrm{mV}$. All these charac- teristics support the direct antioxidant access of ALA to all tissues in organism, especially in plasma.

The measurements of SOD activities in chicken plasma show a constant increase from the start. On day 40 the activity is $18 \%$ greater than on day 16 . In the case of fortified fodder the activities of SOD were reduced. The lowest value was obtained in the group administered with ALA, a little higher activity was obtained in the case of fodder supplemented with ALA and $\mathrm{CoQ}_{10}$ and the smallest reduction in activity of SOD was measured in the group with $\mathrm{CoQ}_{10}$, Table 4. According to our opinion the possible explanation may be that the increase of SOD in control group was the result of stronger oxidative stress during the raise, and the reduction of SOD activities could be a result of the preventive effect of LWMA ( $\mathrm{CoQ}_{10}$ and ALA) in the antioxidant network.

In our experimental work a large amount of data were collected. In order to simplify the interpretation of obtained data we prepared a simplified presentation scheme. Pre-experimental values (starting values) measured at the start on the day 16 were taken as hundred percent. All measurements collected on the days 28 and 40 were normalized to the starting values of $100 \%$ on the day 16 . In the final step values of the relative changes were added. Obtained sums represent the integral changes which appeared at each measured parameter, during the 40 day chicken production raise and 25 days of administration of fortified fodder. In presented results it is necessary to consider that relative percents may often show an excessive estimation, but predicted trends are correct. It is shown that the basic concentrations of ALA decreased, which is seen in control group and also in $\mathrm{CoQ}_{10}$ group. A very high increase was recorded when fodder with ALA and combination of ALA and $\mathrm{CoQ}_{10}$ were used. According to our expectation $\mathrm{CoQ}_{10}$ additive cannot exert influence on the level of ALA. In the case of simultaneous application of $\mathrm{CoQ}_{10}$ and ALA the synergistic effect is seen, but is not so pronounced as in the case of addition of pure ALA (Figure 4).



Figure 4. Relative changes of concentration of three net antioxidants (ALA, CoQ 10 , Vitamin E), cholesterol and glucose and changes of activities of some enzymes (SOD, GPX) and total antioxidant capacity (TAC) in chicken plasma during the experiment are shown. Three test groups were fed with food fortified with ALA, CoQ ${ }_{10}$ and combination of both substances. All measurements were normalized to the starting values.

While observing the changes in total $\mathrm{CoQ}_{10}$ concentrations it is seen that during the raise period basic level of total $\mathrm{CoQ}_{10}$ increased. Administration of $\mathrm{CoQ}_{10}$ additive provoked a very high increase of blood level of $\mathrm{CoQ}_{10}$. A significant increase was recorded in ALA test group. When both additives were used simultaneously the total increase in $\mathrm{CoQ}_{10}$ concentration was higher than in ALA group and lower than in $\mathrm{CoQ}_{10}$ group. Non-additive increase may be a result of synergistic effect of both substances in antioxidant network.

During the raise the concentration of $\alpha$-tocopherol in chicken blood plasma increased, which is seen in the control group. Fodder additives increased the integral level of $\alpha$-tocopherol. Once again, it is seen that the combination of two additives with antioxidant properties did not produce additive result and the final effect was the result of a synergistic action. It is possible to notice a very high protective effect of ALA.

The level of cholesterol decreased comparably in all four groups during the experiment. This means that selected fodder additives had no effect on cholesterol plasma level in our experiment.

A very meaningful is a small increase of glucose concentration in test groups consuming $\mathrm{CoQ}_{10}$ and combination of $\mathrm{CoQ}_{10}$ and ALA. Final concentration is much smaller than the concentration in the control group. In the case of pure ALA the overall decrease was recorded. This is in good correlation with a data from literature in which a positive effect of ALA on reduction of glucose in blood is observed. Lower blood level of glucose is the result of deactivation of substances blocking the insulin penetration in cells. This action can have a very positive effect in diabetes type 2 .

Changes in enzyme activities recorded in determinations 
of SOD, GPx in TAC show the positive effect of applied additives with antioxidant activities on antioxidant network. Outstanding results were obtained with the use of ALA. These results show the strong influence of ALA with active tiol groups on the antioxidant defense.

Some preliminary determination of plasma concentrations of lutein and zeaxanthine in chicken plasma were also made. Both carotenoids are important components of chicken fodder. Collected results show that the sum of both carotenoids decrease during the raise in all four groups. When fodder additives $\mathrm{CoQ}_{10}$ and ALA were used the decrease was smaller than in the control group (Table 3).

At the beginning of our experimental raise we did not plan to measure the plasma level of carotenoids, because we tried to collect as much as possible the information about chemical antioxidant. Later we found out that also the measurement of carotenoids may be a convenient and useful indication of the body's overall antioxidant status. The reason for this is that carotenoids are delivered to tissues by LDL circulating in the blood and their concentrations are correlated with the amounts of the other fat-soluble antioxidants in the body such as vitamin E or $\mathrm{CoQ}_{10}$. Therefore, increased levels of carotenoids reflect overall levels of antioxidant defense and diminished oxidative stress. In addition, non invasive methods have been developed based on an optical method known as Resonance Raman Spectroscopy [40]. This method has been used for many years in research laboratories for carotenoid investigations in biological systems using optical signals, called raman signals. These signals identify the unique molecular structure of carotenoids, allowing their measurement without interference by other molecular substances.

In the next step we intend to develop an in-line control system which will monitor the intensity of oxidative stress. For this reason we need to know the correlation between concentration of carotenoids and concentrations of LWMA. If we succeed, this will be an enormously important development, since the presence of scanners for use in the field studies brings the possibility of in-line assessing antioxidant and nutritional status of animals during the raise.

\section{CONCLUSIONS}

In our research work we assume that participating antioxidants form a network which carry out regulation, inducibility, interactivity and balance between the members. To test such hypothesis it was necessary to develope suitable methodologies for assessing the amount of antioxidants and their activity in tissues and biological fluids. Obtained results may give us more rational recommendations for dietary intake, and help to explain the effects of specific antioxidants. Today, still many questions accompany the beneficial or harmful effects of LMWA supplementation.

Experiments on animal were carried out in accordance with the animal protection law, which is valid in the Republic of Slovenia and is controlled by the Ethic Commitee of the Ministry of Agriculture, Forestry and Food of the Republic of Slovenia.

\section{ACKNOWLEDGEMENTS}

This work was supported by the Slovenian Research Agency (Research Project L1-2174) and the Perutnina Ptuj, d.d. The authors wish to thank Dr. Roman Glaser, Brigita Vindiš-Zelenko and Boštjan Donša from Perutnina Ptuj, d.d.

\section{REFERENCES}

[1] Davies, K.J. (1995) Oxidative stress: The paradox of aerobic life. Free Radicals and Oxidative Stress: Environment, Drugs and Food Additives, 61, 1-31.

[2] Halliwell, B. (2006) Reactive species and antioxidants. Redox biology is a fundamental theme of aerobic life. Plant Physiology, 141, 312-322. doi:10.1104/pp.106.077073

[3] Sies, H. (1997) Oxidative stress: Oxidants and antioxidants. Experimental Physiology, 82, 291-295.

[4] Packer, L. and Colman, C. (1999) The Antioxidant Miracle. John Wiley \& Sons, New York, 1-30.

[5] Bhagavan, H.N. and Chopra, R.K. (2006) Coenzyme Q ${ }_{10}$ : Absorption, tissue uptake, metabolism and pharmacokinetics. Free Radical Research, 40, 445-453. doi:10.1080/10715760600617843

[6] Ernster, L. and Dallner, G. (1995) Biochemical, Physiological and Medical Aspects of Ubiquinone Function. Biochimica Et Biophysica Acta-Molecular Basis of Disease, 1271, 195-204. doi:10.1016/0925-4439(95)00028-3

[7] Crane, F.L. (2001) Biochemical functions of coenzyme $\mathrm{Q}(10)$. Journal of the American College of Nutrition, 20, 591-598.

[8] Bentinger, M., Brismar, K. and Dallner, G. (2007) The antioxidant role of coenzyme Q. Mitochondrion, 7, S41S50. doi:10.1016/j.mito.2007.02.006

[9] Lenaz, G., Fato, R., Formiggini, G. and Genova, M.L. (2007) The role of Coenzyme Q in mitochondrial electron transport. Mitochondrion, 7, S8-S33. doi:10.1016/j.mito.2007.03.009

[10] Olson, R.E. and Rudney, H. (1983) Biosynthesis of Ubiquinone. Vitamins and Hormones, 40, 1-43. doi:10.1016/S0083-6729(08)60431-8

[11] Prošek, M., Šmidovnik, A., Fir Milivojevič, M., Stražišar, M., Golc-Wondra, A., Andrenšek, S. and Žmitek, J. (2005) New water-soluble form of coenzyme $\mathrm{Q}_{10}$ in the form of an inclusion complex with beta-cyclodextrin, process, of preparing, and use of thereof. Patent No. 21783.

[12] Prošek, M., Butinar, J., Lukanc, B., Fir Milivojevič, M., Milivojevič, L., Kriman, M. and Šmidovnik, A. (2008) Bioavailability of water-soluble $\mathrm{CoQ}_{10}$ in beagle dogs. Journal of Pharmaceutical and Biomedical Analysis, 47, 


\section{8-922. doi:10.1016/j.jpba.2008.04.007}

[13] Žmitek, J., Šmidovnik, A., Fir, M., Prošek, M., Zmitek, K., Walczak, J. and Pravst, I. (2008) Relative bioavailability of two forms of a novel water-soluble coenzyme Q10. Annals of Nutrition and Metabolism, 52, 281-287. doi:10.1159/000129661

[14] Packer, L., Witt, E.H. and Tritschler, H.J. (1995) Alpha-Lipoic Acid as a Biological Antioxidant. Free Radical Biology and Medicine, 19, 227-250. doi:10.1016/0891-5849(95)00017-R

[15] Biewenga, G.P., Haenen, G.R. and Bast, A. (1997) The pharmacology of the antioxidant lipoic acid. General Pharmacology, 29, 315-331. doi:10.1016/S0306-3623(96)00474-0

[16] Kagan, V.E., Shvedova, A., Serbinova, E., Khan, S., Swanson, C., Powell, R. and Packer, L. (1992) Dihydrolipoic Acid-A universal antioxidant both in the membrane and in the aqueous phase-Reduction of peroxyl, ascorbyl and chromanoxyl radicals. Biochemical Pharmacology, 44, 1637-1649. doi:10.1016/0006-2952(92)90482-X

[17] Jazbec, P., Šmidovnik, A., Puklavec, M., Križman, M., Šribar, J., Milivojevič, L. and Prošek, M. (2009) HPTLC and HPLC-MS Quantification of Coenzyme $\mathrm{Q}_{10}$ and Cholesterol in Fractionated Chicken-Breast Tissue. Journal of Planar Chromatography-Modern Tlc, 22, 395-398. doi:10.1556/JPC.22.2009.6.1

[18] Jazbec K.P. (2011) Influence of added $\mathrm{CoQ}_{10}$ on its content in chicken tissues and reducing oxidative stress during raising. Ph.D. Thesis, University of Ljubljana, Ljubljana.

[19] Weber, C., Jakobsen, T.S., Mortensen, S.A., Paulsen, G. and Holmer, G. (1994) Antioxidative effect of dietary coenzyme $\mathrm{Q}_{10}$ in human blood-plasma. International Journal for Vitamin and Nutrition Research, 64, 311-315.

[20] Navari-Izzo, F., Quartacci, M.F. and Sgherri, C. (2002) Lipoic acid: A unique antioxidant in the detoxification of activated oxygen species. Plant Physiology and Biochemistry, 40, 463-470. doi:10.1016/S0981-9428(02)01407-9

[21] Islam, M.T. (2009) Antioxidant activities of dithiol alphalipoic acid. Bangladesh Journal of Medical Science, 8, 36. doi:10.3329/bjms.v8i3.3982

[22] Littarru, G.P. and Tiano, L. (2007) Bioenergetic and antioxidant properties of coenzyme $\mathrm{Q}_{10}$ : Recent developments. Molecular Biotechnology, 37, 31-37. doi:10.1007/s12033-007-0052-y

[23] Geng, A.L., Guo, Y.M. and Yang, Y. (2004) Reduction of ascites mortality in broilers by coenzyme $\mathrm{Q}_{10}$. Poultry Science, 83, 1587-1593.

[24] Geng, A.L. and Guo, Y.M. (2005) Effects of dietary coenzyme $Q_{10}$ supplementation on hepatic mitochondrial function and the activities of respiratory chain-related enzymes in ascitic broiler chickens. British Poultry Science, 46, 626-634. doi:10.1080/00071660500273292

[25] Kamisoyama, H., Honda, K., Kitaguchi, K. and Hasegawa, S. (2010) Transfer of Dietary Coenzyme $\mathrm{Q}_{10}$ into the Egg Yolk of Laying Hens. Journal of Poultry Science, 47, 28-33. doi:10.2141/jpsa.009037
[26] Hamano, Y., Sugawara, S., Kamota, Y. and Nagai, E. (1999) Involvement of lipoic acid in plasma metabolites, hepatic oxygen consumption, and metabolic response to a beta-agonist in broiler chickens. British Journal of Nutrition, 82, 497-503.

[27] Kotnik, D., Šmidovnik, A., Jazbec-Križman, P., Križman, M. and Prošek, M. (2011) Direct analysis of carbohydrates in animal plasma by ion chromatography coupled with mass spectrometry and pulsed amperometric detection for use as a non-invasive diagnostic tool. Journal of Chromatography B-Analytical Technologies in the Biomedical and Life Sciences, 879, 3700-3706. doi:10.1016/j.jchromb.2011.10.010

[28] Mosca, F., Fattorini, D., Bompadre, S. and Littarru, G.P. (2002) Assay of coenzyme $Q_{10}$ in plasma by a single dilution step. Analytical Biochemistry, 305, 49-54. doi:10.1006/abio.2002.5653

[29] Karpinska, J., Mikoluc, B., Motkowski, R. and Piotrowska-Jastrzebska, J. (2006) HPLC method for simultaneous determination of retinol, alpha-tocopherol and coenzyme $\mathrm{Q}_{10}$ in human plasma. Journal of Pharmaceutical and Biomedical Analysis, 42, 232-236. doi:10.1016/j.jpba.2006.03.037

[30] Chang, H.T., New, L.S., Neo, A.H., Goh, C.W., Browne, E.R. and Chan, E.C.Y. (2010) A sensitive LC/MS/MS bioanalysis assay of orally administered lipoic acid in rat blood and brain tissue. Journal of Pharmaceutical and Biomedical Analysis, 51, 754-757. doi:10.1016/j.jpba.2009.09.028

[31] Paglia, D.E. and Valentine, W.N. (1967) Studies on the quantitative and qualitative characterization of erythrocyte glutathione peroxidase. Journal of Laboratory and Clinical Medicine, 70, 158-169.

[32] McCord, J.M. and Fridovich, I. (1969) The utility of superoxide dismutase in studying free radical reactions. I. Radicals generated by the interaction of sulfite, dimethyl sulfoxide, and oxygen. Journal of Biological Chemistry, 244, 6056-6063.

[33] Kotnik, D. (2011) Optimization of the pulsed amperometric detection and determination of the selected carbohydrates with ion chromatography. Ph.D. Thesis, University of Ljubljana, Ljubljana.

[34] Kotnik, D., Šmidovnik, A., Jazbec-Križman, P., Križman, M. and Prošek, M. (2011) Overview of the development and application of the hyphenated techniques in nutriational analysis. Acta Chimica Slovenica, 58, 203-211.

[35] Tang, P.H., Miles, M.V., DeGrauw, A., Hershey, A. and Pesce, A. (2001) HPLC analysis of reduced and oxidized coenzyme $\mathrm{Q}_{10}$ in human plasma. Clinical Chemistry, 47, 256-265.

[36] Menke, T., Niklowitz, P., Adam, S., Weber, M., Schluter, B. and Andler, W. (2000) Simultaneous detection of ubiquinol-10, ubiquinone-10, and tocopherols in human plasma microsamples and macrosamples as a marker of oxidative damage in neonates and infants. Analytical Biochemistry, 282, 209-217. doi:10.1006/abio.2000.4579

[37] Hagen, T.M., Vinarsky, V., Wehr, C.M. and Ames, B.N. (2000) (R)-alpha-Lipoic acid reverses the age-associated increase in susceptibility of hepatocytes to tert-butylhy- 
droperoxide both in vitro and in vivo. Antioxidants \& Redox Signaling, 2, 473-483.

doi:10.1089/15230860050192251

[38] Koppenol, W.H. and Butler, J. (1985) Energetics of interconversion reactions of oxyradicals. Advances in Free Radical Biology \& Medicine, 1, 91-131. doi:10.1016/8755-9668(85)90005-5

[39] Buettner, G.R. and Jurkiewicz, B.A. (1996) Catalytic metals, ascorbate and free radicals: Combinations to avoid.
Radiation Research, 145, 532-541. doi: $10.2307 / 3579271$

[40] Bentz, B.G., Diaz, J., Ring, T.A., Wade, M., Kennington, K., Burnett, D.M., McClane, R. and Fitzpatrick, F.A. (2010) Fiberoptic resonance Raman spectroscopy to measure carotenoid oxidative breakdown in live tissues. Cancer Prevention Research, 3, 529-538.

doi:10.1158/1940-6207.CAPR-09-0157 